\title{
Antigenicity and functional properties of $\beta$-lactoglobulin conjugated with fructo-oligosaccharides in relation to conformational changes
}

\author{
J. Z. Zhong, Y. J. Xu, W. Liu, C. M. Liu, ${ }^{1}$ S. J. Luo, ${ }^{1}$ and Z. C. Tu \\ State Key Laboratory of Food Science and Technology, Nanchang University, Nanchang 330047, China
}

\begin{abstract}
Bovine $\beta$-lactoglobulin ( $\beta$-LG) was conjugated with fructo-oligosaccharides (FOS) by Maillard reaction to investigate the relationship among antigenicity, functional properties, and conformational changes of $\beta$-LG. When comparing the antigenicity of $\beta-\mathrm{LG}$ conjugated with FOS at different ratios, the lowest antigenicity of $\beta$-LG was observed at a ratio of $1: 4$, which was about 7 times lower than that of the control $\beta$-LG. Thus, the ratio of $1: 4$ was chosen to conjugate $\beta-L G$ with FOS, and the functional properties and conformational changes of $\beta$-LG-FOS conjugates were investigated. The functional properties (solubility, emulsifying ability, and emulsion stability) of $\beta-L G$ were enhanced after conjugation with FOS. Furthermore, the molecular weight of $\beta$-LG increased from 18.4 to $19.9 \mathrm{kDa}$ after conjugation with FOS, as evaluated by sodium dodecyl sulfate-PAGE and mass spectrometry. Partial unfolding of $\beta$-LG occurred after conjugation with FOS, as reflected by the quenching of fluorescence, the red-shift of fluorescence spectra, and the increase of $\beta$-strands, which may contribute to the decrease in antigenicity and the improvement of functional properties.
\end{abstract}

Key words: $\beta$-lactoglobulin, antigenicity, functional properties, conformation

\section{INTRODUCTION}

$\beta$-Lactoglobulin, a major whey protein found in milk (Wal, 2004), is a valuable ingredient in food manufacture because of its high content of essential amino acids and versatility in terms of functional properties (emulsifying ability, foaming ability, and gelling ability; Moro et al., 2011). In spite of this, industrial application of $\beta-\mathrm{LG}$ is limited by its high antigenicity (Wal, 2002). Several efforts have been made in recent years to reduce the antigenicity of $\beta-\mathrm{LG}$ and thus increase

\footnotetext{
Received October 12, 2012.

Accepted January 19, 2013.

${ }^{1}$ Corresponding authors: luoshunjing@yahoo.com.cn
}

the degree of applicability in the food industry. The common modification methods can be organized into 2 categories: chemical modification of the protein ( $\mathrm{Li}$ et al., 2011) and physical treatments, such as heating or high pressure (Zhong et al., 2011).

Covalent chemical modification is one of the most important chemical modification methods used to modify the functional properties of protein; agents include polyethylene glycol (Kumar et al., 2009), polysaccharides (Jones et al., 2010), monosaccharides (Corzo-Martinez et al., 2012), and oligosaccharides. By enhancing the function of the proteins simultaneously, covalent chemical modification of protein is an effective approach to adjust the antigenicity of allergens. Some reports indicate that covalent modification reduced the antigenicity of icarapin, $\beta-\mathrm{LG}$, and whey protein by conjugation with polyethylene glycol (Wong et al., 2012), carboxymethyl dextran (Kobayashi et al., 2001), and maltose (Li et al., 2011), respectively. Recently, oligosaccharides used in conjugating with $\beta$-LG have included alginic acid oligosaccharide (Hattori et al., 2004), phosphoryl oligosaccharide (Yoshida et al., 2005), acidic oligosaccharides (Hattori et al., 2004), and galacto-oligosaccharides (Moreno et al., 2008). Very limited data are available on the changes in antigenicity and functional properties of $\beta-\mathrm{LG}$ conjugated with fructo-oligosaccharides (FOS). Fructo-oligosaccharides are commonly used as a sweetener and a prebiotic dietary supplement in dairy products. When used as sweeteners, FOS have been shown to have minimal effect on blood sugar levels in individuals with diabetes.

In previous work in our laboratory, we observed that the functional properties of whey protein had a significant relation with its conformation (Liu et al., 2011). In addition, high pressure had a significant influence on the antigenicity of $\beta$-LG (Zhong et al., 2011). We found that changes in antigenicity of $\beta-L G$ were related to the aggregation and conformational changes of protein (Zhong et al., 2012). However, for covalent chemical modification of protein, current research focuses primarily on modifying the functional properties and antigenicity of $\beta$-LG by conjugation with different materials. Little information is available on the relation- 
ship among conformation, antigenicity, and functional properties of $\beta$-LG conjugated with different materials, especially $\beta$-LG-FOS conjugates.

Therefore, the present study was undertaken to further unravel the relationship among antigenicity, functional properties, and conformation of $\beta$-LG. For this purpose, $\beta$-LG was modified by conjugation with FOS. The effect of conjugation with FOS on antigenicity, solubility, and emulsifying properties of $\beta$-LG was investigated in relation to conformational changes of $\beta$-LG, which was characterized by SDS-PAGE, quadrupole time-of-flight (Q-TOF)-mass spectrometry, intrinsic fluorescence spectra, and circular dichroism spectra.

\section{MATERIALS AND METHODS}

\section{Materials and Reagents}

Bovine $\beta$-LG (L3908) and FOS were obtained from Sigma Chemical Company (St. Louis, MO). Fructo-oligosaccharides have the structure $1^{\mathrm{F}}-(1-\beta-$ fractofranosyl $)_{\mathrm{n}-1}$ sucrose; that is, 1-kestose $(\mathrm{n}=2$, $\left.\mathrm{GF}_{2}\right)$, nystose $\left(\mathrm{n}=3, \mathrm{GF}_{3}\right), 1^{\mathrm{F}}$ - $\beta$-fractofranosyl nystose $\left(\mathrm{n}=4, \mathrm{GF}_{4}\right)$, and so on. All other reagents were of analytical grade, and solutions were made in doubledistilled water.

\section{$\beta-L G$ Glycation}

$\beta$-Lactoglobulin was conjugated with FOS under the following conditions according to Hattori et al. (2004) and Li et al. (2011) with slight modifications. The different mass ratios of $\beta-\mathrm{LG}$ and FOS (1:0, 1:1, 1:2, 1:4, $1: 6,1: 8$, and 1:10) were dissolved in $600 \mathrm{~mL}$ of distilled water and then lyophilized. The mixtures were incubated at $50^{\circ} \mathrm{C}$ at a relative humidity of $79 \%$ for $24 \mathrm{~h}$. After dialysis against distilled water and lyophilization, a crude $\beta$-LG-FOS conjugate was obtained. Free oligosaccharides were removed by salting out. The crude sample was dissolved in distilled water, and ammonium sulfate was added to a final concentration of $5 \mathrm{M}$. The precipitate was recovered by centrifugation $(48,400$ $\times g$ for $30 \mathrm{~min}$ ) at $20^{\circ} \mathrm{C}$. The purified conjugate was obtained after dialysis against distilled water and lyophilization. All glycation experiments were performed in triplicate.

\section{Antigenicity Analysis}

The antigenicity of different $\beta$-LG samples was estimated by an indirect competitive ELISA. Polyclonal IgY antibodies of rabbit, monospecific for $\beta$-LG, were applied, detecting the antigenic response of $\beta-\mathrm{LG}$
(Zhong et al., 2011). Microtiter plates with 96 wells (flat-bottomed; Costar, Corning, Corning, NY) were coated with $100 \mu \mathrm{L} /$ well of $1 \mu \mathrm{g} / \mathrm{mL}$ antigen and were incubated overnight at $4^{\circ} \mathrm{C}$. Residual free binding sites were blocked with $1 \%$ pig gelatin in PBS/Tween solution (PBST) for $30 \mathrm{~min}$ at room temperature. The wells of the plates were washed 6 times with PBST. Competition was initiated by adding $50 \mu \mathrm{L}$ of either the standard or a sample solution containing 0.25 to 50 $\mu \mathrm{g} / \mathrm{mL}$ of $\beta-\mathrm{LG}$ in PBST and $50 \mu \mathrm{L}$ of anti- $\beta$-LG-IgY $(10 \mu \mathrm{g} / \mathrm{mL})$ to the wells. The plates were incubated overnight at $4^{\circ} \mathrm{C}$. After removing the solutions, the wells were washed 6 times with PBST. A solution of $100 \mu \mathrm{L}$ of purified anti-rabbit IgG (A6154, Sigma Chemical Co.), diluted 1:10,000 in PBST, was added and the plates were incubated for $2 \mathrm{~h}$ at $37^{\circ} \mathrm{C}$. After washing, $50 \mu \mathrm{L}$ of $\mathrm{H}_{2} \mathrm{O}_{2}$-urea solution and $50 \mu \mathrm{L}$ of tetramethylenbenzidine solution were immediately added to each well. The reaction was stopped by adding $100 \mu \mathrm{L}$ of 1 $M$ sulfuric acid. Absorption was measured at $450 \mathrm{~nm}$.

The antigenic response of the samples was calculated from a standard curve of $\beta$-LG, for which a linear logarithmic correlation was observed in the range of 0.01 to $400 \mu \mathrm{g} / \mathrm{mL}$ for $\beta$-LG. All analyses were carried out in triplicate, and the averaged values were converted to concentration equivalents in micrograms per milliliter.

\section{Analysis of Functional Properties}

Protein Solubility. Native and glycated $\beta-\mathrm{LG}$ were diluted in distilled water $(1 \mathrm{mg} / \mathrm{mL})$. The $\mathrm{pH}$ of the solution was then adjusted to the desired values $(\mathrm{pH} 3$, 5,7 , and 9) using concentrated $\mathrm{HCl}$ or $\mathrm{NaOH}$. Samples were centrifuged for $20 \mathrm{~min}$ (Hitachi Co., Tokyo, Japan) at $8,000 \times g$. Protein content in the supernatant was determined by the Lowry method using BSA as the standard (Lowry et al., 1951; Tang and Sun, 2011). Solubility was expressed as milligrams of soluble protein per $1 \mathrm{mg}$ of total protein. All determinations were conducted 3 times.

Emulsifying Properties. Emulsifying activity in$\operatorname{dex}(\mathbf{E A I})$ and emulsion stability index (ESI) of $\beta$-LG were determined as described by Pearce and Kinsella (1978) and Wang et al. (2008) with slight modifications. For analysis, $5 \mathrm{~mL}$ of $1 \mathrm{mg} / \mathrm{mL}$ protein solution in $50 \mathrm{~m} M$ phosphate buffer $(\mathrm{pH} 7.0)$ and $1 \mathrm{~mL}$ of corn oil were emulsified. Fifty microliters of emulsion was taken from the bottom of the emulsion and diluted $(1: 100, \mathrm{vol} / \mathrm{vol})$ in $0.1 \%$ SDS solution. After shaking the emulsion in a vortex mixer for $5 \mathrm{~s}$, the absorbance of the dilute emulsion was measured at $500 \mathrm{~nm}$ using a spectrophotometer (DU-64; Beckman Instruments Inc., Fullerton, CA). The EAI and ESI values were calculated using the following equations: 


$$
\begin{gathered}
\operatorname{EAI}\left(\mathrm{m}^{2} / \mathrm{g}\right)=\frac{2 \times 2.303 \times A_{0} \times \mathrm{DF}}{c \times \phi \times(1-\theta) \times 10,000}, \\
\operatorname{ESI}(\min )=\frac{A_{0}}{A_{0}-A_{10}} \times 10,
\end{gathered}
$$

where DF was the dilution factor (100), $c$ was the initial concentration of protein $(\mathrm{g} / \mathrm{mL}), \varnothing$ was the optical path $(0.01 \mathrm{~m}), \theta$ was the fraction of oil used to form the emulsion (0.25), and $A_{0}$ and $A_{10}$ were the absorbance of diluted emulsions at 0 and $10 \mathrm{~min}$, respectively. Measurements were performed in, at least, triplicate.

\section{Analysis of Conformational Changes}

$\boldsymbol{S D S}-\boldsymbol{P A} \boldsymbol{G E}$. Sodium dodecyl sulfate-PAGE was carried out to determine the molecular weight of the $\beta-\mathrm{LG}$, as described by Laemmli (1970) and used by Li et al. (2008). Electrophoresis was run with a 5\% (wt/ vol) stacking gel and 15\% (wt/vol) separating gel, with currents of 15 and $35 \mathrm{~mA}$, respectively. Samples were prepared by mixing $\beta-\mathrm{LG}$ at $1: 1$ ( $\mathrm{vol} / \mathrm{vol})$ ratio with $\mathrm{pH}$ 6.8, $0.5 M$ Tris-HCl, $2 \mathrm{mg}$ of SDS, $2 \mu \mathrm{L}$ of glycerol, 2 $\mu \mathrm{L}$ of $\beta$-mercaptoethanol, and $0.04 \mathrm{mg}$ of bromophenol blue. Samples were heated at $100^{\circ} \mathrm{C}$ for 5 to $10 \mathrm{~min}$ before electrophoresis. After electrophoresis, the gels were stained with $0.25 \%$ Coomassie Brilliant Blue R-250 for at least 30 min in $25 \%$ methanol and $10 \%$ acetic acid and destained with $5 \%$ methanol and $7.5 \%$ acetic acid. The molecular weight markers used were 14, 20, 29, 44, 66 , and $97 \mathrm{kDa}$.

Q-TOF Mass Spectrometry. The method of Medrano et al. (2009) was modified to further determine the molecular weight of $\beta$-LG and $\beta$-LG-FOS conjugate. Protein was analyzed using the Agilent 6538-accurate-mass Q-TOF liquid chromatographymass spectrometer (Agilent Technologies, Waldbronn, Germany). Samples were diluted in a saturated solution of R-cycano-4-hydroxycinnamic acid in $0.1 \%$ trifluoroacetic acid with $33 \%$ acetonitrile. An aliquot of this mixture was spotted onto a stainless steel target, airdried, and subjected to mass determination (Medrano et al., 2009). The monitored mass range was $m / z 100$ to 20,000 .

Circular Dichroism Spectroscopy. Circular dichroism (CD) spectroscopy analyses were run for different $\beta$-LG samples according to Divsalar et al. (2009). The CD spectra of $\beta-\mathrm{LG}$ at $0.1 \mathrm{mg} / \mathrm{mL}$ for far-UV in $10 \mathrm{~m} M$ sodium phosphate buffer, $\mathrm{pH}$ 7.0, were collected using a MOS-450 spectropolarimeter (French Bio-Logic SAS Co., Claix, France), at $22^{\circ} \mathrm{C}$. A cylindrical quartz cuvette with a path length of $0.1 \mathrm{~cm}$ was used for collecting data in the far-UV $(185-250 \mathrm{~nm})$ region. The scanning condition was $1 \mathrm{~nm}$ step resolution for farUV; both scans were performed using a $100 \mathrm{~nm} / \mathrm{min}$ scan rate, $1.0 \mathrm{~nm}$ of bandwidth, and 4 scans, corrected by subtracting the buffer baseline spectrum. The CD data were expressed in terms of mean residual ellipticity $\left([\theta] ;\right.$ mdegree $\left.\cdot \mathrm{cm}^{2} / \mathrm{dmol}\right)$.Structure predictions from CD spectra were obtained using the Contin LL program (de la Hoz and Netto, 2008).

Intrinsic Fluorescence. Fluorescence analyses were performed for $\beta$-LG samples as described by de la Hoz and Netto (2008). Fluorescence measurements were carried out in a Hitachi spectrofluorimeter F-4500 (Hitachi) using a 10-mm square quartz cells and protein concentration of $1 \mathrm{mg} / \mathrm{mL}$ in phosphate buffer (10 $\mathrm{m} M, \mathrm{pH}$ 7.0). The excitation wavelength was $280 \mathrm{~nm}$; the emission spectrum was scanned from 300 to 450 $\mathrm{nm}$, using 5-nm bandwidth, with excitation and emission slits of 2.5 and $5.0 \mathrm{~nm}$, respectively, and at a scan speed of $240 \mathrm{~nm} / \mathrm{min}$.

\section{Statistical Analysis}

All glycation experiments were performed in triplicate. All glycation samples and control samples were analyzed in triplicate. The statistical analysis was established by ANOVA.

\section{RESULTS AND DISCUSSION}

\section{Effect of Conjugation with FOS on Antigenicity of $\beta-L G$}

The antigenicity of $\beta-\mathrm{LG}$ conjugated with different ratio of FOS measured by ELISA is shown in Figure 1. The conjugation of FOS had a significant effect on the antigenicity of the $\beta$-LG solutions. The antigenicity of the control $\beta$-LG was $145 \mu \mathrm{g} / \mathrm{mL}$. After conjugation with FOS, the antigenicity of $\beta-L G$ decreased greatly as the mass ratio increased. A remarkable decrease in the antigenicity of $\beta$-LG $(26.8 \mu \mathrm{g} / \mathrm{mL})$ was observed when $\beta$-LG was conjugated with FOS at the ratio of $1: 4$, about 7 times lower than that of the control $\beta$-LG. However, when the conjugation ratio was $<1: 4$, the antigenicity of $\beta$-LG increased with the increase in the amount of FOS added.

According to Li et al. (2011), the conjugation ratio between protein and sugar is an important variable. It was reported that the average number of sugar units bound per $\beta$-LG monomer depended on the conjugation ratio between $\beta$-LG and sugar. For example, Medrano et al. (2009) found that when $\beta$-LG was modified by glucose, the number of sugars per protein molecule increased from 7 to 15 with an increasing ratio. Moreover, the antigenicity of $\beta$-LG was also changed with the changing 


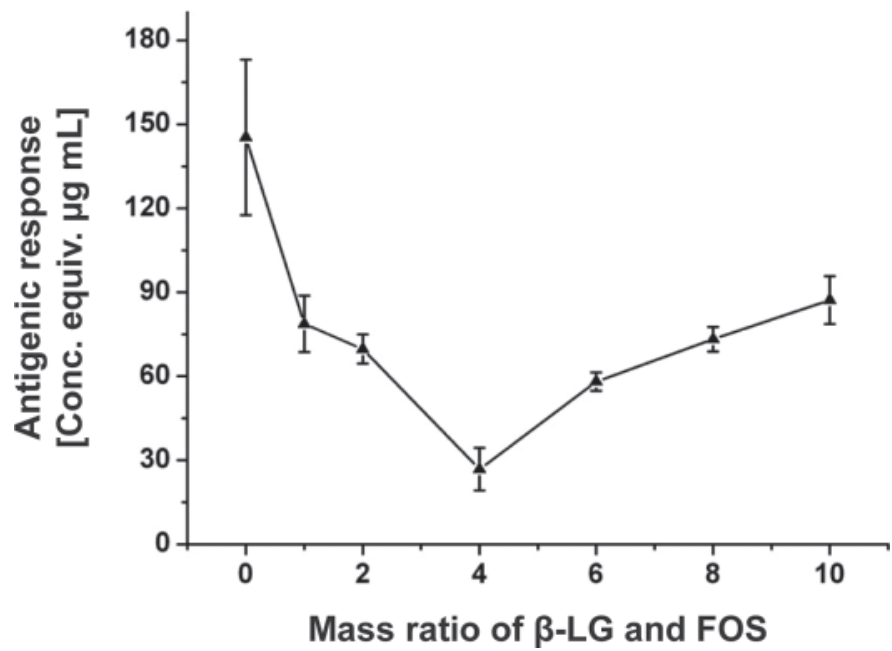

Figure 1. The effect on antigenicity of different ratios of $\beta$-LG conjugated with fructo-oligosaccharides (FOS).

ratio, because of the varying degrees of glycosylation of $\beta$-LG with sugar. Li et al. (2011) investigated the effect of the weight ratio of whey protein and maltose on the antigenicity of $\beta-L G$. Minimum antigenicity was obtained when the weight ratio was 1.04:1; antigenicity was reduced to about one-sixth of the original value. Similarly, in this study, the weight ratio had a significant effect on the antigenicity of $\beta$-LG. Although the conjugation of $\beta$-LG with FOS can lead to a decrease in antigenicity, it was still unknown whether $\beta$-LG-FOS conjugates can improve the functional properties of $\beta$-LG. Furthermore, our previous work found that the antigenicity and functional properties of whey protein and $\beta$-LG were related to the conformational changes (Liu et al., 2011; Zhong et al., 2011, 2012). To better decrease the antigenicity of $\beta-\mathrm{LG}$, the ratio of $1: 4$ was chosen to conjugate $\beta-\mathrm{LG}$ with FOS. Then, the functional properties and conformational changes of $\beta$-LG-FOS conjugates were investigated.

\section{Effect of Conjugation with FOS on the Functional Properties of $\beta-L G$}

Solubility Properties. The solubility of protein is a critical factor in the acceptability of dairy beverages, ice cream mix, and whipping cream. The solubility of $\beta$-LG and $\beta$-LG-FOS at $\mathrm{pH} 3.0,5.0,7.0$, and 9.0 was evaluated (Figure 2). The control $\beta-\mathrm{LG}$ and $\beta$-LGFOS conjugate exhibited typical $\mathrm{pH}$ solubility profiles, where solubility was minimal at $\mathrm{pH} 5$ and progressively increased at $\mathrm{pH} 3,7$, and 9 . The minimal solubility at $\mathrm{pH} 5$ was clearly related to the known phenomenon of protein aggregation or precipitation around the isoelectric point $(\mathrm{pI})$. The solubility data in this study

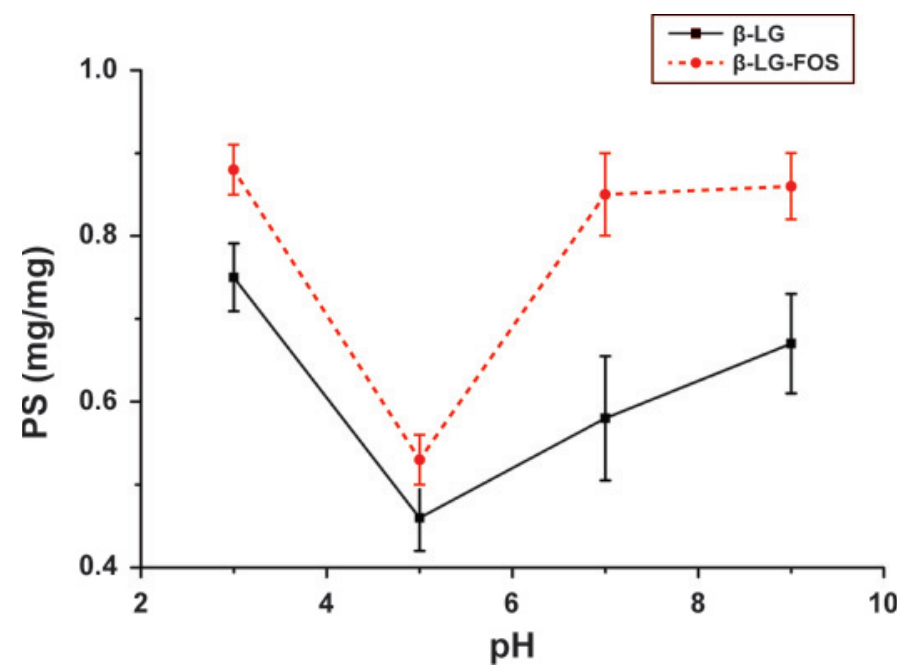

Figure 2. The effect of different $\mathrm{pH}$ on the solubility of control $\beta$-LG and $\beta$-LG after conjugation with fructo-oligosaccharides (FOS) at a ratio of 1:4. $\mathrm{PS}=$ protein solubility. Color version available in the online PDF.

indicated that conjugation with FOS significantly improved the solubility of $\beta$-LG over the whole $\mathrm{pH}$ range studied. For example, the solubility of $\beta-\mathrm{LG}$ increased to $17,15,50$, and $25 \%$ when the $\mathrm{pH}$ was $3,5,7$, and 9 , respectively. This result is in agreement with that of Jimenez-Castano et al. (2005), who observed that $\beta$-LG modified with dextran exhibited higher solubility over the whole $\mathrm{pH}$ range studied. The solubility of the conjugate increased after glycation treatment, which might due to the introduction of hydrophilic sugar molecules in the protein.

Emulsifying Properties. The influence of conjugation with FOS on the emulsifying activities (EAI and ESI) of $\beta$-LG was evaluated. As shown in Table 1, EAI increased significantly after conjugation of $\beta$-LG with FOS; EAI was almost twice as high in the conjugated $\beta-\mathrm{LG}$ as in the control $\beta-\mathrm{LG}$. The EAI values of control $\beta$-LG and $\beta$-LG-FOS conjugate were $6.5 \times 10^{5}$ and $11.2 \times 10^{5} \mathrm{~m}^{2} / \mathrm{g}$, respectively. The ESI of control $\beta-\mathrm{LG}$ was $98.2 \mathrm{~min}$, whereas the ESI of $\beta$-LG-FOS conjugate increased to $109.0 \mathrm{~min}$. These results were in accordance with the observations of Hattori et al. (1996), who reported increased emulsifying ability in case of $\beta$-LG-alginic acid conjugate compared with the emulsions of $\beta$-LG alone. It has also been reported that the emulsifying properties of $\beta-\mathrm{LG}$ are slightly improved by conjugation with carboxymethyl dextran (Nagasawa et al., 1996).

According to some reports, protein conformation is related to the emulsifying properties of protein (Fachin and Viotto, 2005). In our previous work, we showed that conformational changes can influence the func- 
Table 1. Emulsifying properties and percentage content of secondary structures of control $\beta$-LG and $\beta$-LG after conjugation with fructo-oligosaccharides (FOS) at a ratio of 1:4

\begin{tabular}{|c|c|c|c|c|c|c|}
\hline \multirow[b]{2}{*}{ Sample } & \multicolumn{2}{|c|}{ Emulsifying activity ${ }^{1}$} & \multicolumn{4}{|c|}{ Secondary structure } \\
\hline & $\underset{\left(\times 10^{5} \mathrm{~m}^{2} / \mathrm{g}\right)}{\text { EAI }}$ & $\begin{array}{c}\text { ESI } \\
(\min )\end{array}$ & $\begin{array}{c}\alpha \text {-Helix } \\
(\%)\end{array}$ & $\begin{array}{c}\beta-\text { Strands } \\
(\%)\end{array}$ & $\begin{array}{c}\text { Turns } \\
(\%)\end{array}$ & $\begin{array}{c}\text { Unordered } \\
(\%)\end{array}$ \\
\hline$\beta-\mathrm{LG}$ & $6.5 \pm 0.78$ & $98.2 \pm 8.8$ & $14.3 \pm 0.30$ & $33.2 \pm 0.25$ & $21.8 \pm 0.40$ & $30.6 \pm 0.51$ \\
\hline$\beta$-LG-FOS & $11.2 \pm 2.6$ & $109.0 \pm 10$ & $15.7 \pm 0.32$ & $41.1 \pm 0.55$ & $21.6 \pm 0.38$ & $23.8 \pm 0.90$ \\
\hline
\end{tabular}

${ }^{1} \mathrm{EAI}=$ emulsifying activity index; ESI $=$ emulsion stability index.

tional properties of protein (Liu et al., 2011). Thus, it is very important to elucidate the conformational changes of $\beta$-LG conjugates in detail. For this purpose, the conformational changes of $\beta$-LG were analyzed below.

\section{Effect of Conjugation with FOS on Conformational Changes of $\beta-L G$}

Changes in Molecular Weight. The conjugation of $\beta$-LG with FOS was analyzed by SDS-PAGE and mass spectrometry. According to some reports, when protein and sugar react, the amino residue of the protein and the reducing end of the sugar are expected to attach and form a covalent bond (Kato et al., 1993). This reaction contributed to the increase in molecular weight of $\beta$-LG-oligosaccharide conjugates. Figure 3a shows SDS-PAGE patterns of $\beta$-LG conjugated with FOS. The bands of $\beta$-LG-FOS conjugates moved further in the gel compared with control $\beta$-LG lane, suggesting that FOS bonded to $\beta-\mathrm{LG}$ during the reaction. The molecular weight of $\beta$-LG is approximately 18.4 $\mathrm{kDa}$, which can be observed in Figure 3a and Figure 3b. The mass spectra (Figure 3b) indicated that FOS was conjugated with $\beta$-LG, the molecular weight of which increased from 18.4 to $19.9 \mathrm{kDa}$. We then investigated the changes of secondary and tertiary structure of $\beta-\mathrm{LG}$ when conjugated with FOS by glycation treatment.

Changes in Secondary Structure. Circular dichroism spectra for the control $\beta$-LG and $\beta$-LG-FOS are shown in Figure 4. $\beta$-Lactoglobulin, consisting of 9 anti-parallel $\beta$-strands and 1 major $\alpha$-helix at the C-terminus of the molecule, is a predominantly $\beta$-sheet protein (Shibayama, 2008). The CD spectra showed a negative extreme around $216 \mathrm{~nm}$, a crossing zero dichroism at $203 \mathrm{~nm}$, and a positive maximum around $195 \mathrm{~nm}$, indicating a high content of $\beta$-strands and in accordance with the secondary structure content in Table 1 . The spectrum of the $\beta$-LG-FOS conjugates showed an increase in ellipticity and a shift of the positive and negative maximums to a higher wavelength compared with the control samples. According to Considine et al. (2007), the trough at $216 \mathrm{~nm}$ gradually broadened and deepened, accompanied by the unfold- ing of $\beta$-LG. Thus, Figure 4 indicates that $\beta$-LG may also be partially unfolded. Furthermore, the content of $\alpha$-helix did not significantly change. The percentage content of $\beta$-strands increased from 33.2 to $41.1 \%$ after conjugation with FOS, while the percentage content of unordered structure decreased from 30.6 to $23.8 \%$. Different treatments affected the secondary structure of $\beta$-LG differently. For example, we observed previously that high pressure treatment could induce a slight increase of $\beta$-strands, from 33.2 to $38.4 \%$ (Zhong et al., 2012). In addition, Hattori et al. (2004) indicated that the secondary structure of $\beta$-LG was almost completely maintained after its conjugation with alginic acid oligosaccharide and phosphoryl oligosaccharides.

The antigenicity of the $\beta$-LG depends on the epitopes, which were widely spread along the 162 AA (Clement et al., 2002) and throughout the $\beta$-LG conformation (Sélo et al., 1999). The epitopes AA 41-60 and AA 102-124 form a protruding loop between $\beta$-strands $\mathrm{C}$ and $\mathrm{D}$ on the surface of the molecule (Wal, 2001). In addition, the $\beta$-strands of $\beta$-LG contained other epitopes, particularly 2 conformation-sensitive epitopes (Clement et al., 2002). When the content of $\beta$-strands increases with the partial unfolding of the protein, some epitopes may be buried after conjugation with FOS, which may lead to the decrease of the antigenicity.

Changes in Tertiary Structure. The intrinsic fluorescence of $\beta-\mathrm{LG}$ is mainly excited from tryptophan (Trp) residues, which are sensitive to the surrounding environment. The fluorescence spectra of control $\beta-\mathrm{LG}$ and $\beta$-LG-FOS were observed and the results are shown in Figure 5. Conjugation with FOS contributed to a decrease in relative fluorescence intensity. The relative fluorescence intensities of control $\beta$-LG and $\beta$-LG-FOS conjugate were 937.8 and 535.2 , respectively. In addition, the wavelength of fluorescence emission peak was redshifted from $336 \mathrm{~nm}$ (control $\beta$-LG) to $343 \mathrm{~nm}$ ( $\beta$-LGFOS conjugate). According to Hattori et al. (2004), the shift of fluorescence wavelength for maximum emission reveals the altered conformation of $\beta$-LG. Similarly, the conjugated $\beta$-LG-FOS in the present experiment exhibited a red shift of the wavelength, revealing the tertiary structure around the Trp residues (19Trp and 61Trp). 

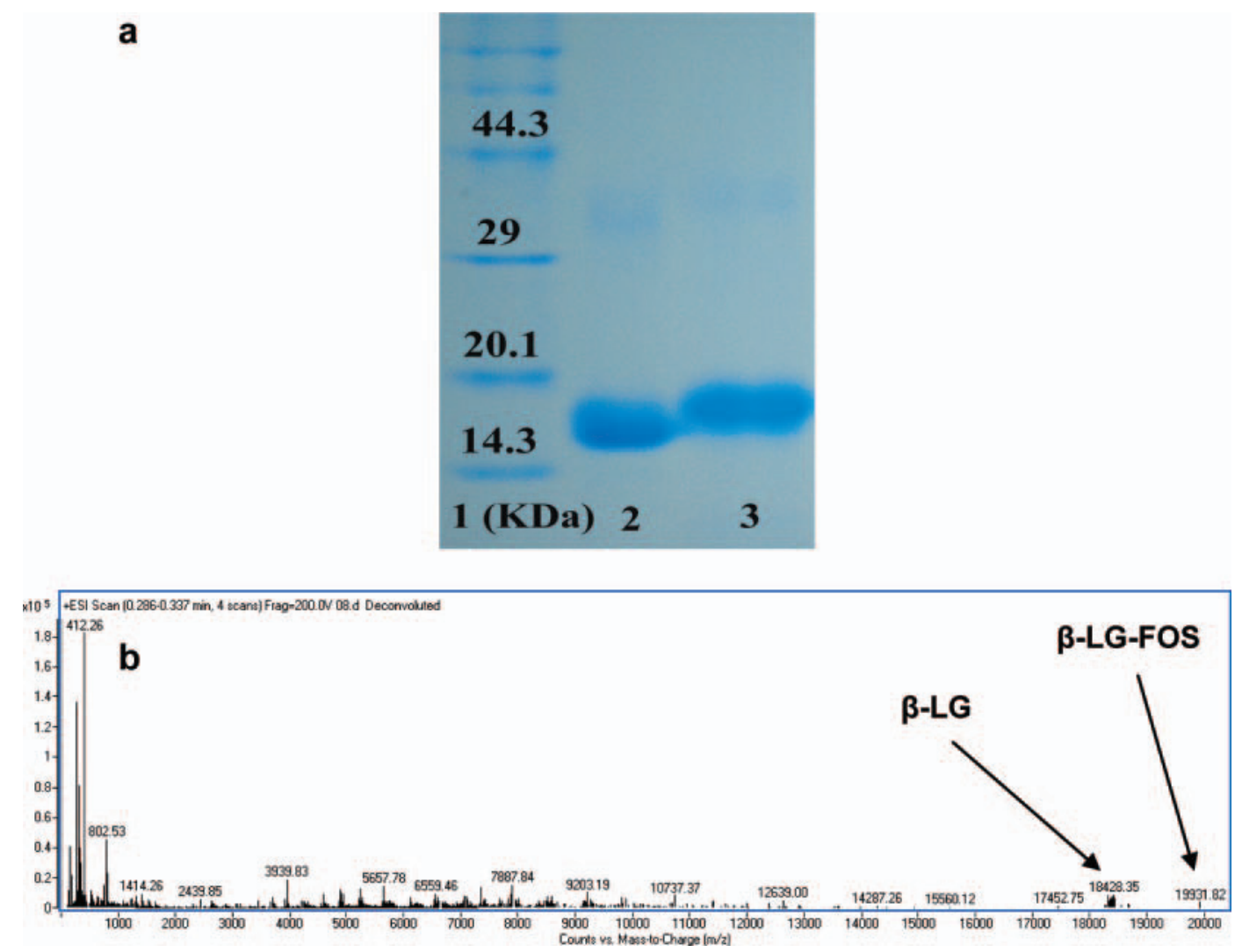

Figure 3. (a) SDS-PAGE analysis: lane $1=$ standard protein markers of different molecular weights; lanes 2 and 3: control $\beta$-LG and $\beta$-LG conjugated with fructo-oligosaccharides (FOS) at the ratio of 1:4; (b) quadrupole time-of-flight/mass spectrum of $\beta$-LG conjugated with FOS at a ratio of 1:4. Color version available in the online PDF.

It is well known that the fluorescence intensity of Trp is quenched by polar solvents (Szabó et al., 2006). $\beta$-Lactoglobulin might be partially unfolded during the glycation treatment so that Trp residues were exposed to the polar environment, which results in quenching of fluorescence. Similarly, Liu et al. (2009) reported that as the protein partially unfolded, the conformational changes around the Trp residues were accompanied by quenching of fluorescence. Furthermore, Hattori et al. (2004) observed that the fluorescence intensity changes of $\beta$-LG were different after conjugation with alginic acid oligosaccharide compared with phosphoryl oligosaccharides. The fluorescence intensity of $\beta$-LG conjugated with phosphoryl oligosaccharides was similar to that of native $\beta$-LG, whereas that of $\beta$-LG conjugated with alginic acid oligosaccharide was lower than that of native $\beta$-LG.

According to some reports, the carbohydrate-binding sites in the $\beta$-LG were mainly identified to be residue Lys (Hattori et al., 2004). The decrease of fluorescence intensity in the case of glycation conjugates was considered to have been due to a shielding effect by oligosaccharide chain bound to ${ }^{60}$ Lys in this conjugate (Hattori

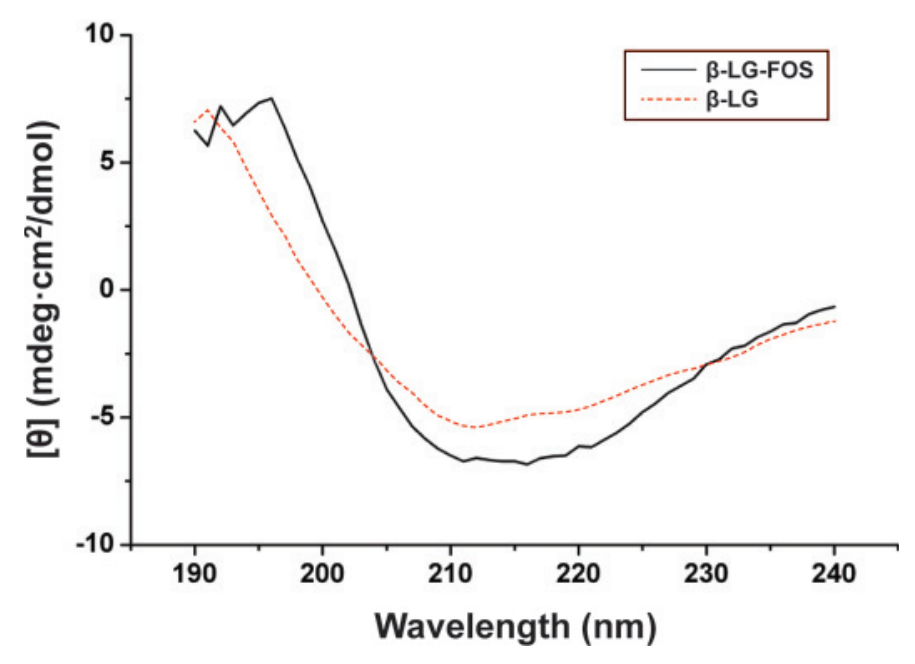

Figure 4. Circular dichroism (CD) spectra analysis of control $\beta-\mathrm{LG}$ and $\beta$-LG after conjugation with fructo-oligosaccharides (FOS) at a ratio of 1:4. The CD data were expressed in terms of mean residual ellipticity $\left([\theta] ;\right.$ mdegree $\left.\cdot \mathrm{cm}^{2} / \mathrm{dmol}\right)$. Color version available in the online PDF. 


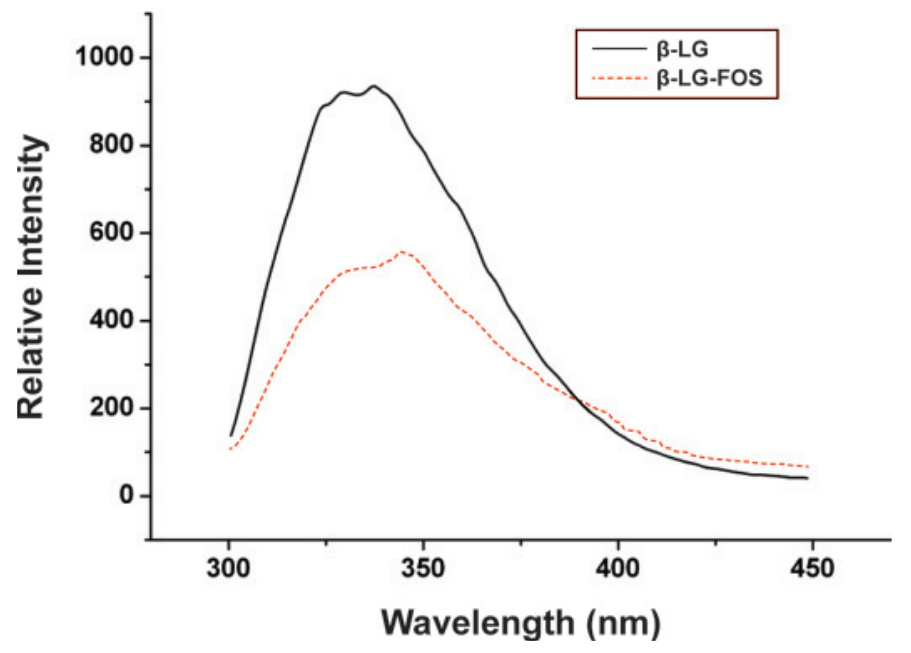

Figure 5. Intrinsic fluorescence spectroscopic analysis of control $\beta$-LG and $\beta$-LG after conjugation with fructo-oligosaccharides (FOS) at a ratio of 1:4. Color version available in the online PDF.

et al., 2004). The best recognized epitopes were the fragments AA102-124, AA41-60, and AA149-162 (Sélo et al., 1999). Binding of FOS to ${ }^{60}$ Lys may mask some epitopes (e.g., AA41-60) around Lys residues. The masking of some residues contributed to a decrease of the antigenicity of $\beta-\mathrm{LG}$.

The results in the current study indicated that $\beta-\mathrm{LG}$ partially unfolded and FOS may have opportunities to bind with hidden Lys residues. After binding with those hidden residues, a larger area of protein may be covered by hydrophilic FOS, which contributes to the increase of solubility. Furthermore, the partially unfolded protein may contribute to better dispersion and hydration of $\beta$-LG after conjugation with FOS, resulted in a greater solubility. According to some reports, the emulsifying activity of milk protein increases upon modification with sugars, probably because of the superior water-binding properties of these glycol-conjugates in oil-in-water emulsions (Hiller and Lorenzen, 2010). The increase in emulsifying activity of $\beta-\mathrm{LG}$ may also be due to the superior water-binding properties of FOS in this study.

\section{CONCLUSIONS}

The antigenicity of $\beta$-LG decreased greatly after conjugation with FOS as the mass ratio increased. A remarkable decrease in the antigenicity of $\beta-L G$ was observed following conjugation with FOS at a ratio of 1:4. The solubility data in this study indicate that conjugation with FOS significantly increased the solubility of $\beta$-LG over the whole $\mathrm{pH}$ range studied. The emulsifying activity and emulsion stability of $\beta$-LG were also improved. In addition, the results of SDS-PAGE and mass spectrometry revealed that the molecular weight of $\beta$-LG increased from 18.4 to $19.9 \mathrm{kDa}$ after conjugation with FOS by covalent bond. The partial unfolding of $\beta$-LG after conjugation with FOS was reflected by quenching of fluorescence intensity, the red-shift of fluorescence spectra, and the increase of $\beta$-strands. The conformational changes of $\beta$-LG-FOS may be related to the decrease in antigenicity and the increase in solubility and emulsifying properties.

\section{ACKNOWLEDGMENTS}

This study was supported financially by the National Natural Science Foundation of China (31071573), the Research Program of Sate Key Laboratory of Food Science and Technology, Nanchang University (SKLF-MB-201004), and the Research Fund for the Doctoral Program of Higher Education of China (20103601110002).

\section{REFERENCES}

Clement, G., D. Boquet, Y. Frobert, H. Bernard, L. Negroni, J. M. Chatel, K. Adel-Patient, C. Creminon, J. M. Wal, and J. Grassi 2002. Epitopic characterization of native bovine $\beta$-lactoglobulin. J. Immunol. Methods 266:67-78.

Considine, T., H. A. Patel, H. Singh, and L. K. Creamer. 2007. Influence of binding conjugated linoleic acid and myristic acid on the heat- and high-pressure-induced unfolding and aggregation of B-lactoglobulin B. Food Chem. 102:1270-1280.

Corzo-Martinez, M., C. Carrera Sanchez, F. Javier Moreno, J. M. Rodriguez Patino, and M. Villamiel. 2012. Interfacial and foaming properties of bovine $\beta$-lactoglobulin: Galactose Maillard conjugates. Food Hydrocoll. 27:438-447.

de la Hoz, L., and F. M. Netto. 2008. Structural modifications of $\beta$-lactoglobulin subjected to gamma radiation. Int. Dairy J. 18:1126-1132.

Divsalar, A., A. A. Saboury, F. Ahmad, and A. A. Moosavi-Movahedi. 2009. Effects of temperature and chromium (III) ion on the structure of bovine $\beta$-lactoglobulin A. J. Braz. Chem. Soc. 20:17821789 .

Fachin, L., and W. H. Viotto. 2005. Effect of $\mathrm{pH}$ and heat treatment of cheese whey on solubility and emulsifying properties of whey protein concentrate produced by ultrafiltration. Int. Dairy J. $15: 325-332$.

Hattori, M., Y. Aiba, K. Nagasawa, and K. Takahashi. 1996. Functional improvement of alginic acid by conjugating with $\beta$-lactoglobulin. J. Food Sci. 61:1171-1176.

Hattori, M., S. Miyakawa, Y. Ohama, H. Kawamura, T. Yoshida, K. To-O, T. Kuriki, and K. Takahashi. 2004. Reduced immunogenicity of $\beta$-lactoglobulin by conjugation with acidic oligosaccharides. J. Agric. Food Chem. 52:4546-4553.

Hiller, B., and P. C. Lorenzen. 2010. Functional properties of milk proteins as affected by Maillard reaction induced oligomerisation. Food Res. Int. 43:1155-1166.

Jimenez-Castano, L., R. Lopez-Fandino, A. Olano, and M. Villamiel. 2005. Study on $\beta$-lactoglobulin glycosylation with dextran: Effect on solubility and heat stability. Food Chem. 93:689-695.

Jones, O. G., U. Lesmes, P. Dubin, and D. J. McClements. 2010. Effect of polysaccharide charge on formation and properties of biopolymer nanoparticles created by heat treatment of $\beta$-lactoglobulinpectin complexes. Food Hydrocoll. 24:374-383. 
Kato, A., K. Minaki, and K. Kobayashi. 1993. Improvement of emulsifying properties of egg-white proteins by the attachment of polysaccharide through Maillard reaction in a dry state. J. Agric. Food Chem. 41:540-543.

Kobayashi, K., A. Hirano, A. Ohta, T. Yoshida, K. Takahashi, and M. Hattori. 2001. Reduced immunogenicity of $\beta$-lactoglobulin by conjugation with carboxymethyl dextran differing in molecular weight. J. Agric. Food Chem. 49:823-831.

Kumar, V., V. K. Sharma, and D. S. Kalonia. 2009. Effect of polyols on polyethylene glycol (PEG)-induced precipitation of proteins: Impact on solubility, stability and conformation. Int. J. Pharm. 366:38-43.

Laemmli, U. K. 1970. Cleavage of structural proteins during assembly of head of bacteriophage-T4. Nature 227:680-685.

Li, X., Z. L. Luo, H. B. Chen, and Y. S. Cao. 2008. Isolation and antigenicity evaluation of $\beta$-lactoglobulin from buffalo milk. Afr. J. Biotechnol. 7:2258-2264.

Li, Z., Y. Luo, and L. Feng. 2011. Effects of Maillard reaction conditions on the antigenicity of $\alpha$-lactalbumin and $\beta$-lactoglobulin in whey protein conjugated with maltose. Eur. Food Res. Technol. 233:387-394

Liu, C. M., J. Z. Zhong, W. Liu, Z. C. Tu, J. Wan, X. F. Cai, and X. Y. Song. 2011. Relationship between functional properties and aggregation changes of whey protein induced by high pressure microfluidization. J. Food Sci. 76:E341-E347.

Liu, W., J. H. Liu, C. M. Liu, Y. J. Zhong, W. L. Liu, and J. Wan. 2009. Activation and conformational changes of mushroom polyphenoloxidase by high pressure microfluidization treatment. Innov. Food Sci. Emerg. 10:142-147.

Lowry, O. H., N. J. Rosebrough, A. L. Farr, and R. J. Randall. 1951. Protein measurement with the Folin phenol reagent. J. Biol. Chem. 193:265-275.

Medrano, A., C. Abirached, L. Panizzolo, P. Moyna, and M. C. Anon. 2009. The effect of glycation on foam and structural properties of $\beta$-lactoglobulin. Food Chem. 113:127-133.

Moreno, F. J., J. Eduardo Quintanilla-Lopez, R. Lebron-Aguilar, A. Olano, and M. L. Sanz. 2008. Mass spectrometric characterization of glycated $\beta$-lactoglobulin peptides derived from galacto-oligosaccharides surviving the in vitro gastrointestinal digestion. J. Am. Soc. Mass Spectrom. 19:927-937.

Moro, A., G. D. Baez, P. A. Busti, G. A. Ballerini, and N. J. Delorenzi. 2011. Effects of heat-treated $\beta$-lactoglobulin and its aggregates on foaming properties. Food Hydrocoll. 25:1009-1015.

Nagasawa, K., K. Takahashi, and M. Hattori. 1996. Improved emulsifying properties of $\beta$-lactoglobulin by conjugating with carboxymethyl dextran. Food Hydrocoll. 10:63-67.
Pearce, K. N., and J. E. Kinsella. 1978. Emulsifying properties of proteins evaluation of a turbidimetric technique. J. Agric. Food Chem. 26:716-723.

Sélo, I., G. Clement, H. Bernard, J. M. Chatel, C. Creminon, G. Peltre, and J. M. Wal. 1999. Allergy to bovine $\beta$-lactoglobulin: Specificity of human IgE to tryptic peptides. Clin. Exp. Allergy 29:1055-1063

Shibayama, N. 2008. Circular dichroism study on the early folding events of $\beta$-lactoglobulin entrapped in wet silica gels. FEBS Lett. 582:2668-2672.

Szabó, A., M. Kotormán, I. Laczkó, and L. M. Simon. 2006. Spectroscopic studies of stability of papain in aqueous organic solvents. J. Mol. Catal. B Enzym. 41:43-48.

Tang, C. H., and X. Sun. 2011. A comparative study of physicochemical and conformational properties in three vicilins from Phaseolus legumes: Implications for the structure-function relationship. Food Hydrocoll. 25:315-324.

Wal, J. M. 2001. Structure and function of milk allergens. Allergy $56: 35-38$.

Wal, J. M. 2002. Cow's milk proteins/allergens. Ann. Allergy Asthma Immunol. 89:3-10.

Wal, J. M. 2004. Bovine milk allergenicity. Ann. Allergy Asthma Immunol. 93:S2-S11.

Wang, X. S., C. H. Tang, B. S. Li, X. Q. Yang, L. Li, and C. Y. Ma. 2008. Effects of high-pressure treatment on some physicochemical and functional properties of soy protein isolates. Food Hydrocoll. 22:560-567.

Wong, K.-L., H. Li, K.-K. K. Wong, T. Jiang, and P.-C. Shaw. 2012. Location and reduction of icarapin antigenicity by site specific coupling to polyethylene glycol. Protein Pept. Lett. 19:238-243.

Yoshida, T., Y. Sasahara, S. Miyakawa, and M. Hattori. 2005. Reduced $\mathrm{T}$ cell response to $\beta$-lactoglobulin by conjugation with acidic oligosaccharides. J. Agric. Food Chem. 53:6851-6857.

Zhong, J., C. Liu, W. Liu, X. Cai, Z. Tu, and J. Wan. 2011. Effect of dynamic high-pressure microfluidization at different temperatures on the antigenic response of bovine $\beta$-lactoglobulin. Eur. Food Res. Technol. 233:95-102.

Zhong, J. Z., W. Liu, C. M. Liu, Q. H. Wang, T. Li, Z. C. Tu, S. J. Luo, X. F. Cai, and Y. J. Xu. 2012. Aggregation and conformational changes of bovine $\beta$-lactoglobulin subjected to dynamic high-pressure microfluidization in relation to antigenicity. J. Dairy Sci. 95:4237-4245. 